\title{
APRESENTAÇÃO
}

\section{NEGACIONISMO: HISTÓRIA, HISTORIOGRAFIA \\ E PERSPECTIVAS DE PESQUISA}

\section{Negationism: History, Historiography and Research Perspectives}

\author{
Patrícia Valim* \\ Alexandre de Sá Avelar** \\ Berber Bevernage $e^{* * *}$
}

Como certos passados, sistematicamente escrutinados pelos historiadores, amplamente debatidos e largamente documentados, podem ser simplesmente negados ou apresentados como invenções motivadas por interesses escusos? O que leva grupos e indivíduos a duvidarem da existência do Holocausto, da ditadura militar brasileira, dos incontáveis genocídios ao redor do mundo ou da escravidão que, ao longo de mais de três séculos, moldou as formas sociais do capitalismo moderno? Quais são as operações intelectuais, afetivas, políticas e ideológicas que envolvem e inscrevem os desafios e interrogações lançados pelos negacionismos à história, como conhecimento organizado do passado, aos seus usos políticos, apropriações e condições de produção da verdade?

Estas questões estiveram nas origens deste dossiê e agora são aprofundadas pelos artigos que o compõem. Eles apresentam um arco diversificado de reflexões acerca das variadas formas de visibilidade do negacionismo e do revisionismo ideológico no espaço público, bem como se propõem a pensar o papel da escrita da história e dos historiadores em seu enfrentamento. Evidentemente, explorar todas as respostas possíveis para as perguntas anteriores nos

\footnotetext{
* Universidade Federal de Bahia (UFBA), Salvador, Brasil. patricia.valim@ufba.br <http://orcid. org/0000-0002-7615-1142>

** Universidade Federal de Uberlândia (UFU), Uberlândia, Brasil. alexandre.avelar@uol.com.br $<$ https://orcid.org/0000-0002-1441-2087>

*** Universidade de Gent (UGent), Bélgica. berber.bevernage@ugent.be < https://orcid.org/0000-00023201-3119>
} 
levaria a perscrutar um domínio inalcançável de análises produzidas por áreas que, ao longo das últimas décadas, procuraram decifrar a complexidade do fenômeno negacionista. Nossos objetivos são outros.

Pretendemos, sobretudo, historicizar tal fenômeno, destacando suas permanências, tensões, cisões e rupturas ao longo do tempo. Se formos bem-sucedidos em nossa tarefa, nossos leitores poderão captar um processo em movimento, em contínua reconfiguração e que, em nossa temporalidade, assumiu, em muitos lugares, os contornos de uma forma específica - negacionista - de governamentalidade da vida política. Ainda que reconheçamos que o negacionismo é altamente complexo e diverso, e que periodizações podem ser mais um produto da vontade do historiador do que uma característica da realidade histórica, o esforço de historicização aqui realizado pretende demonstrar algumas possibilidades analíticas que possam nos orientar na apreensão do fenômeno sob uma temporalidade mais longa, capaz, inclusive, de anteceder os próprios marcos usualmente aceitos no debate.

\section{A palavra e AS COISAS: UMA PROPOSTA DE historicizaÇÃo}

O termo negacionismo, para se referir a grupos e indivíduos que negavam a existência das câmaras de gás e o extermínio em massa dos judeus durante o regime nazista, foi popularizado pelo historiador francês Henry Rousso (1987, p. 166). A palavra passou a ser usada em sentido contrário ao empregado pelos próprios negacionistas, que se viam como fundadores de uma "escola revisionista” (a denominação é do negacionista Roubert Faurisson) e pretendiam conferir credibilidade intelectual e científica ao que não passava de falsificação e de distorção de evidências ${ }^{1}$. Ainda assim, como lembra Enzo Traverso, eles conseguiram contaminar a linguagem e criar confusão no debate público. Isso ocorreu, em parte, pela própria ambiguidade da noção de revisionismo que, longe de se restringir ao debate acadêmico e historiográfico, é também um fenômeno político relacionado às práticas e aos discursos que questionam as relações que as sociedades estabelecem com seus passados (Traverso, 2019, p. 97).

Um aspecto importante para o argumento que desenvolveremos ao longo desta introdução foi assinalado por Henry Rousso: é apenas uma verdade parcial o fato de que o negacionismo seja vinculado ao excepcional caráter do extermínio dos judeus. Ele já aparecia, sob outras formas, na negação da responsabilidade do governo turco pelo massacre dos armênios em 1915 e, nos dias de hoje, se converteu em "uma modalidade discursiva, um modo de representação do passado e de percepção do presente” (Rousso, 2020, p. xiii). 
Esse aspecto nos sugere, portanto, que o negacionismo histórico pode ser pensado como um mosaico de falas, práticas e representações mobilizadas com o objetivo de legitimar certas leituras dos nossos passados sensíveis - sobretudo de suas violências, seus extermínios e dominação dos mais vulneráveis.

A proposição de uma visão ampliada do fenômeno negacionista não deve elidir o papel desempenhado pelas sistemáticas formas de negação do extermínio dos judeus, iniciadas durante a II Guerra. Elas foram praticadas por uma geração de falsificadores do passado que, além de isentar os alemães das responsabilidades pelo extermínio de milhões de judeus, elaborou um modus operandi que seria incorporado tanto pelos negacionistas posteriores quanto por seus aliados da extrema-direita em diversos países. Seria óbvio, mas não menos imprescindível, assinalar que o apagamento dos vestígios do genocídio sempre foi um objetivo dos próprios nazistas, e não foi outro o sentido do conhecido discurso de Himmler, em 1943, quando afirmou que a "solução final” seria uma página não escrita na gloriosa história alemã. Tratou-se, portanto, do acionamento da máquina negacionista que pretendeu produzir a "destruição do fato, da noção de fato, da factualidade do fato" (Nichanian, 2006, p. 9).

Este primeiro momento se estendeu para o imediato pós-guerra, quando principalmente grupos antissemitas de extrema-direita procuraram, mesmo sem terem envolvimento direto com os crimes que negavam, manter viva a ideologia nazista, desvencilhando-a dos horrores dos campos de concentração. Este negacionismo sistemático começou a ser elaborado paralelamente à definição do paradigma "onusiano" do chamado crime dos crimes: o genocídio, tal como estabelecido pela primeira vez na General Assembly Resolution 96 (I) da ONU, realizada em dezembro de 1946 e, depois, confirmado na Convention on the Prevention and Punishment of the Crime of Genocide, adotada por meio da Resolução 260 (III) da Assembleia Geral da ONU a 9 de dezembro de 1948 (Loureiro; Zagni, 2019). Estas resoluções foram frutos, sobretudo, da pressão política da comunidade internacional dos penalistas após a II Guerra, e se originaram, em grande medida, da obra do jurista Raphaël Lemkin, que, em Axis Rule in Occupied Europe (1944), estabeleceu as bases do conceito de genocídio adotado pela $\mathrm{ONU}^{2}$.

A definição do crime de genocídio por um organismo internacional como a ONU assinalou um marco do Direito Internacional, importante e controverso instrumento jurídico contra a impunidade em tribunais internacionais, e abriu caminho para a primeira geração dos "genocides scholars", cujas publicações serão fundamentais, no campo das ciências humanas, para o debate em 
torno do genocídio como o crime dos crimes (sobretudo o Holocausto) - como demonstra Leo Kuper (1981), para quem a compreensão jurídica do conceito onusiano de genocídio seria o ponto de partida para a sua prevenção.

William A. Schabas (2000) demonstrou que, a partir da Convenção de 1948, os processos criminais de genocídio decorreram do reconhecimento de que a perseguição de minorias étnicas, nacionais e religiosas não era apenas moralmente ultrajante, mas também deveria ser legalmente responsabilizada, à medida que o genocídio é invariavelmente realizado a mando e com a cumplicidade das autoridades políticas. Também devemos considerar os indivíduos que, ligados direta ou indiretamente a essas autoridades, cometeram crimes de genocídio e, por essa razão, têm todo o interesse em negá-los, produzindo esquecimentos e silêncios, ou falseando relatos de sobreviventes e de testemunhas desses massacres (Loureiro; Zagni, 2019; Schabas, 2000, p. 17).

Por outro lado, como demonstra Lawrence Langer (1995, p. 24), ao analisar os limites do conceito jurídico de genocídio por meio dos genocídios recentes de Ruanda e de Srebrenica, apenas recentemente as ciências humanas incorporaram ao vocabulário político de suas análises o termo genocídio para designar a morte de milhões de pessoas, além das vítimas do Holocausto: indígenas durante o período colonial, africanos e africanas vítimas do tráfico atlântico e da escravidão, armênios mortos pelo governo otomano a partir de 1915, populações deportadas pelo regime stalinista na URSS. ${ }^{3}$

Desde o final dos anos quarenta até os conhecidos textos de Faurisson na imprensa francesa, no final dos anos setenta, uma série de autores se esforçaram diligentemente para construir um certo discurso "científico" e "hipercrítico" (Rousso, 2016, p. 177; Igounet, 2020, p. 13) que fundamentaria as teses negacionistas a partir de uma revisão profunda do conhecimento historiográfico sobre o destino dos judeus durante a guerra.

Esses negacionistas profissionais ajudaram a estabilizar, no espaço público, algumas explicações que refutariam o que afirmavam ser uma mentira orquestrada pelos judeus: o Holocausto era, sobretudo, uma impossibilidade técnica, já que os campos de concentração jamais tiveram a capacidade para exterminar seis milhões de pessoas; em verdade, as câmaras de gás eram destinadas à desinfecção dos presos; as mortes foram o resultado das próprias condições da guerra e não de um plano industrial de extermínio; e a documentação disponível permitiria demonstrar que a chamada "solução final" não era outra coisa senão a concentração territorial dos judeus em comunidades específicas ou guetos (Bardèche, 1948; Rassinier, 1987; Butz, 1979; Faurisson, 1999; Irving, 1977). 
A repercussão dessas teses foi decisiva para que os negacionistas, ao redor do mundo, passassem a "se apresentar como historiadores críticos, preocupados com a verdade e vítimas de perseguições” (Milman, 2000, p. 145; Atkins, 2008), movimento também impulsionado pela divulgação do pseudocientífico Relatório Leuchter, em 1988, e pelos processos judiciais enfrentados por Robert Faurisson, David Irving, Ernst Zundel, Roger Garaudy, Pedro Varela, Siegfried Ellwanger, entre outros.

Ao mesmo tempo, os historiadores passaram a se posicionar mais incisivamente. A conhecida resposta de Pierre Vidal-Naquet (1988) motivou a publicação de uma série de textos e livros que desmontaram as falácias e as falsificações promovidas pelos negadores do Holocausto (Fresco, 1980; Finkielkraut, 1998 [1982]; Friedländer, 1992; Lispadt, 1994). A tarefa não era, do ponto de vista epistemológico, das mais árduas: as evidências apresentadas pelos negacionistas eram frágeis, descontextualizadas e distorcidas. No entanto, eles não mais poderiam ser tratados como um fenômeno marginal, deslocado e circunscrito a alguns poucos indivíduos.

Para o psicólogo Israel Charny (1992), quando os negacionistas começaram a mobilizar mecanismos subjetivos de negação dos genocídios, vários países conheceram a forma mais difundida de negacionismo histórico: a "negação inocente", que pensa a história a partir dos sentidos e da experiência individual. O negacionismo, neste início de novo milênio, tornou-se mais multifacetado, definindo-se não mais apenas em função dos conhecidos negadores do Holocausto, mas também a partir de uma miríade de formas de negação de outros genocídios e também de reconstruções revisionistas de passados mais ou menos sensíveis em diversos países. Esta fase mais recente pode ser caracterizada a partir de três questões de análise, que dialogam, em maior ou menor grau, com os textos do dossiê.

A primeira delas é o caráter cada vez mais difuso do negacionismo, tanto do ponto de vista geográfico quanto de sua autoria coletiva, em vez da identificação fácil de obras e autores individuais. As manifestações atuais de negação histórica e a luta contra ela se transformaram em fenômenos globais em razão das influências combinadas da globalização, da migração em massa e da ascensão da mídia internacional. Frequentemente, padrões de migração e comunidades diaspóricas desempenham um papel importante no revigoramento global do negacionismo, que, por sua vez, pode reforçar a autoidentificação coletiva e a politização destas comunidades, ampliando as tensões entre elas.

O negacionismo do genocídio armênio, por exemplo, é comum entre migrantes turcos na Europa (ainda que, obviamente, muitos não se engajem nes- 
tas questões) e o seu reconhecimento histórico por vários estados europeus em função, quase sempre, de pressões das comunidades armênia e, em alguns casos, curda - deu origem a mobilizações coletivas, apreensões e coalizações entre essas comunidades diaspóricas (Baser, 2014; Koinova, 2019). Da mesma forma, a presença de diferentes comunidades ruandenses - cuja migração é tanto anterior quanto posterior ao genocídio - fez da Europa (Ocidental) uma arena importante para a criação e disseminação de narrativas conflitantes sobre os massacres em Ruanda, incluindo discussões sobre a existência de genocídio único ou duplo, sobre qual data simbólica deve ser escolhida como seu ponto de partida e quem pode ser considerado vítima (Kuradusenge, 2016).

O surgimento de um cenário midiático-digital global facilitou a ampla disseminação da negação do Holocausto e de outras formas de negacionismo histórico. $\mathrm{O}$ universo virtual não apenas forneceu espaço para a proliferação das mais odiosas e ultrajantes informações, sob um véu relativo de anonimato e impunidade, como também permitiu que muitas mais pessoas pudessem contribuir com esses negacionismos de uma maneira fácil, simplesmente refazendo ou reunindo pedaços de informações encontradas no espaço virtual (Hassan, 2016; Terry, 2017).

Os negacionistas também puderam ver seus pontos de vista e reivindicações confirmados pelo chamado "efeito de câmara de eco", criado pelos algoritmos que sustentam muitas das novas mídias sociais (Schaub; Morisi, 2020). Enquanto a elaboração e a disseminação de formas clássicas de negacionismo e revisionismo históricos frequentemente envolviam investimentos consideráveis (e riscos) para os negacionistas profissionais, os recursos interativos da internet permitiram um modo diferente de produção e expansão destes discursos, com base em contribuições muito mais modestas e menos coordenadas de um grande número de pessoas.

Pode-se questionar a extensão em que as tecnologias de mídia inauguraram uma era da "pós-verdade" radicalmente nova, caracterizada por uma "indiferença à verdade" ou por uma generalizada "morte da expertise" (Gudonis; Jones, 2020; Nichols, 2017). No entanto, está claro que essas novas tecnologias afetaram a maneira como muitas pessoas avaliam a autenticidade das afirmações e como criticam ou reivindicam a autoridade epistêmica. Essas mudanças criaram novas possibilidades para o florescimento do negacionismo histórico e do revisionismo ideológico, e o estudo das suas manifestações atuais deve prestar a devida atenção a este contexto mais amplo de um cenário de mídia em constante mudança.

Uma segunda questão das manifestações recentes de negacionismo his- 
tórico é o fato de elas serem cada vez mais um fenômeno patrocinado pelo Estado. Esta característica não é nova, é claro - pensemos na longa tradição de negação do genocídio armênio pelos governos turcos -, mas parece ter alcançado novos níveis com o aumento global de governos autoritários, ditos populistas. Um dos exemplos deste negacionismo de Estado foi a conferência Review of the Holocaust: Global Vision, sediada em Teerã, em 2006, oficialmente organizada pelo Ministério das Relações Exteriores do Irã, para a qual foram convidados negacionistas de todo o mundo ${ }^{4}$. O evento teve a presença do presidente Mahmoud Ahmadinejad (Küntzel, 2012, p. 235). Igualmente dignos de nota são os esforços dos governos da Polônia e da Hungria, nas últimas duas décadas, para criar histórias oficiais que negam a co-responsabilidade pelo Holocausto, institucionalizando-as através de museus e institutos de pesquisa como a "Casa do Terror", museu em Budapeste, e o Instituto de Memória Nacional, em Varsóvia (Laczó, 2015; Goddeeris, 2018).

Aos exemplos acima poderíamos acrescentar muitos outros de lideranças de Estado engajadas em políticas negacionistas que, em alguns casos, revertem reconhecimentos oficiais e desculpas públicas dados por governos anteriores. Pensemos na controvérsia internacional causada pelo primeiro-ministro do Japão, Shinzo Abe, em 2007, quando afirmou que não havia nenhuma evidência histórica de que as chamadas "mulheres de conforto"5 foram coagidas pelos militares japoneses - fazendo coro, assim, ao crescente negacionismo, praticado desde o início de 1990, por grupos de direita, dos crimes de guerra cometidos pelo exército imperial durante a Segunda Guerra Mundial (Hayashi, 2008).

A construção do negacionismo histórico mais recente no Japão, que minimiza os crimes cometidos pelo estado durante a Guerra Sino-Japonesa e a II Guerra Mundial e impulsiona uma narrativa de vitimização, foi o foco do artigo de Mario Marcello Neto neste dossiê. Seu argumento central é o de que as bombas atômicas lançadas sobre o Japão são o entremeio tanto para negacionistas se apoiarem na ideia de vitimização, quanto para uma historiografia engajada que se dedica a compreender os horrores da guerra e suas dinâmicas (Neto, 2021).

A terceira característica é a relação ambígua entre o negacionismo contemporâneo e a ascensão de uma agenda internacional relacionada às formas de "lidar com o passado", às "políticas de reconhecimento" e à "lembrança moral" (David, 2020a; 2020b; Moon, 2013). A negação histórica é, por um lado, uma reação contra essa agenda, e, por outro, incorpora certos elementos dessas políticas de "enfrentamento do passado" (vergangenheisbewältigung). É notável que 
a atual onda de negacionismo coincide com um período de ênfase política sobre a importância da verdade histórica e do reconhecimento. Esse processo se iniciou na década de 1980 e foi simbolizado pelo surgimento generalizado de comissões da verdade e do princípio jurídico do "direito à verdade"6.

Muitos comentaristas definem o nosso tempo como uma "era de desculpas", dominado por uma "política de arrependimento" segundo a qual os estados, bem como as comunidades e instituições, sentem cada vez mais a necessidade de reconhecer publicamente seus erros históricos e de mostrar sua disposição, sincera ou não, em oferecer alguma reparação material ou simbólica. Outros analistas apontam que esses fenômenos integram um "projeto liberal e hegemônico de memória" (Gibney et al., 2008; Olick, 2013). Esta "memória liberal" possui como um de seus axiomas a ideia de que a paz e a democracia só podem ser obtidas ou salvaguardadas se as sociedades (em transição) chegarem a um acordo com as páginas sombrias de seu passado. Nos últimos anos, essa memória tem sido bastante criticada por estudiosos céticos acerca de sua eficácia na defesa do regime democrático, argumentando, por exemplo, que ela pode levar a novos conflitos ou ser sequestrada para fins autoritários (David, 2020b).

Algumas dessas preocupações parecem de fato se confirmar quando voltamos nosso foco para a atual onda de negacionismos e revisionismos ideológicos de extrema-direita, pois eles perduram ou até florescem em países que fizeram esforços consideráveis para estabelecer iniciativas de reconhecimento histórico oficial, por exemplo, na forma de comissões da verdade, investigações oficiais, desculpas públicas ou programas comemorativos patrocinados pelo Estado. É emblemático o fato de Jair Bolsonaro ter sido eleito presidente apesar, ou possivelmente por causa, do seu negacionismo e de sua banalização da violência estatal durante a ditadura militar no Brasil - e que isso tenha acontecido apenas alguns anos após essa violência ser reconhecida oficialmente por várias iniciativas de revelação da verdade e de reparações públicas, incluindo o relatório da Comissão Nacional da Verdade, divulgado em 2014 (Schneider, 2020).

Os riscos simbólicos e materiais oriundos das políticas de reconhecimento e de reparação - e a reação contra elas - também influenciam os tipos de negacionismos que daí resultam e o que é negado. Essas políticas envolvem disputas não apenas para se provar a "facticidade" de certos eventos, mas também para se obter o reconhecimento de interpretações sociais ou jurídicas específicas a respeito deles - por exemplo, como sendo um "genocídio". Além disso, está em jogo a luta por atribuições específicas de responsabilidade e para mostrar que esses eventos históricos têm implicações no presente que 
exigem retificação. Da mesma forma, a reação contra as políticas de reconhecimento e de reparação muitas vezes provoca não apenas uma "negação literal”, mas também o que Stanley Cohen (2001) chama de "negação interpretativa" e de "negação implicatória".

A "negação interpretativa” não recusa os fatos, mas busca mudar sua interpretação convencional, alterando palavras ou usando eufemismos, por exemplo. A crescente judicialização da história fez da luta para que atrocidades históricas fossem reconhecidas como "genocídio" - ou para que se contestasse essa nomeação - um aspecto central da tensão entre as políticas de reconhecimento e o negacionismo. A "negação "implicatória" se relaciona às implicações morais dos erros e suscita a questão da resposta e da ação correta no presente. Segundo Cohen, a aposta da negação implicatória, em contraste com a negação literal ou interpretativa, não é o conhecimento em si, mas "fazer a coisa 'certa' com esse conhecimento" (Cohen, 2001, p. 9). Em síntese, trata-se de saber se os erros históricos estão relacionados às injustiças ou às desigualdades contemporâneas, se o passado tem uma presença contínua ou obsessiva ou se deveria ser considerado morto e definitivamente enterrado. Esta questão é central, por exemplo, nas discussões sobre a continuação de um "apartheid residual” na África do Sul (Bevernage, 2018), após o seu fim formal, ou nos argumentos a favor ou contra as reparações por escravidão ou colonialismo (Scott, 2020).

Partidos e regimes autoritários de extrema-direita têm se apropriado de algumas técnicas e da retórica do projeto de memória liberal para seus próprios projetos negacionistas ou revisionistas de contramemória ou "memória iliberal” (Rosenfeld, 2021). O paradigma da lembrança moral liberal, e, especialmente, a memória do Holocausto, forneceram a grupos nacionalistas um modelo de sofrimento que poderia ser usado para criar suas próprias narrativas de vitimização. Vários regimes, principalmente na Europa Oriental e na Central, estão cada vez mais emulando os modelos das leis de negação de genocídio, que foram desenvolvidos em democracias liberais ocidentais, a fim de legalmente estabelecer historiografias oficiais nacionalistas (Belavusau; Gliszczyńska-Grabias, 2017).

As leis memoriais ${ }^{7}$, aplicadas aos casos do Holocausto e do genocídio armênio, por exemplo, foram originalmente destinadas a combater a negação histórica, proteger a dignidade das vítimas e inscrever algum nível de expressão de arrependimento nacional em nome da promoção de valores cívicos transnacionais comuns. Essas leis, em países que tiveram regimes comunistas, na Europa, ainda declaram nominalmente ter como objetivo suprimir o negacionismo e defender as vítimas, mas frequentemente são usadas para que estes 
governos reivindiquem sua própria vitimização nacional, desculpem-se de qualquer (co)-responsabilidade pelo Holocausto ou por outras atrocidades em massa, reprimam quaisquer representações históricas além daquelas oficiais e concedam "proteção legal a narrativas nacionais autocongratulatórias tipicamente populistas" (Koposov, 2021, p. 9). Entre os usos autoritários recentes de tais leis memoriais está a chamada "Lei do Holocausto", introduzida na Polônia, em 2018, que incluía um artigo prevendo uma sentença de prisão de até três anos para quem afirmasse a responsabilidade ou a corresponsabilidade dos poloneses pelos crimes cometidos pelo nazismo.

A punição legal aos negacionistas tem suscitado um amplo debate entre historiadores e juristas a respeito da pertinência de se combater a negação dos genocídios por meio de legislação específica. Entre os críticos, alguns argumentos são claramente discerníveis. Em primeiro lugar, as leis anti-negacionistas - e também todas as demais leis "memoriais" - correm o risco de expressar formas oficiais de verdade histórica ou de reconhecimento de memórias consideradas mais apropriadas sobre certos passados. Além disso, essas leis representam uma séria ameaça à liberdade de expressão e de pesquisa, e as sociedades correm o risco de assistir a negacionistas ferrenhos sendo apresentados como mártires do direito à livre manifestação de ideias. Não foram poucos aqueles que atestaram a ineficácia dessas leis: a punição não foi capaz de conter os negacionistas e a crescente internacionalização das diversas formas de negação do passado parece confirmar essa constatação. Os defensores da responsabilização judicial argumentam que, como discursos que incitam ódio contra grupos específicos, os negacionismos representam a perpetuação do crime de genocídio. Além disso, os negacionistas atentam contra a ordem democrática na medida em que visam destruir a existência de uma "comunidade do fato" (Rateau, 2007, p. 48), que se baseia em consensos básicos sobre a verdade de determinados acontecimentos e representa a própria condição de possibilidade da vida institucional (Baruch, 2013; Behrens, 2017; Charny, 1992; Fronza, 2018; Hennebel; Hochmann, 2011; Thus, 2013).

\section{MARCAS BRASILEIRAS}

No conjunto dos negacionismos contemporâneos, as peculiaridades brasileiras constituem um campo amplo e aberto às investigações que possam explorar as variadas estratégias de negação de alguns dos passados sensíveis, como a ditadura militar, a escravidão e os genocídios das comunidades indígenas e negras. As questões discutidas anteriormente, por outro lado, ainda 
que exemplificadas a partir de contextos distintos, conformam algumas características comuns que unem a experiência brasileira a de outros países nos quais o negacionismo se tornou uma forma de gestão da vida política.

É o caso da obra pioneira de Abdias do Nascimento O genocídio do negro brasileiro: processo de um racismo mascarado (2016), publicada pela primeira vez pela Editora Paz \& Terra, em 1978, incontornável para o debate sobre genocídio em perspectiva decolonial. A partir de um conjunto de documentos e dados estatísticos apresentados no ano anterior, durante o "Segundo Festival de Artes e Culturas Negras" realizado em Lagos, Nigéria, Abdias do Nascimento demonstra a retirada do quesito cor/raça do Censo de 1970, durante a ditadura militar, como parte de um conjunto de políticas de Estado constantemente atualizado para o genocídio da população negra, historicamente negado por meio do "mito da democracia racial".

De outro modo, também acreditamos que os pesquisadores dedicados a estudar as manifestações mais recentes do fenômeno negacionista no Brasil não podem desconsiderar a dimensão transnacional dos problemas com os quais lidam, o que se torna visível, por exemplo, quando consideramos as iniciativas da Editora Revisão, da cidade de Porto Alegre, que foi responsável pela publicação de obras negacionistas sobre o Holocausto e as várias teorias conspiratórias que envolviam os judeus (Jesus, 2006).

Neste sentido, a constituição de um campo de estudos sobre o negacionismo no Brasil foi marcada, em seus momentos iniciais, por pesquisadores que priorizaram fundamentalmente, em seus trabalhos, as investigações sobre a negação do extermínio dos judeus no contexto de reflexões mais amplas sobre o regime nazista e o antissemitismo (Nehab, 1988; Carneiro, 2001; Milman, 2004; Moraes, 2009; Neto, 2009). A coletânea organizada por Luís Milman e Paulo Fagundes Vizentini (2000), embora não tenha sido dedicada inteiramente ao negacionismo do Holocausto, constitui-se em uma referência expressiva, sobretudo em função do seu pioneirismo e da articulação com o debate sobre o ressurgimento da extrema-direita neonazista em vários países europeus durante as décadas de 1990 e 2000.

Outra característica importante dos estudos brasileiros sobre a negação do Holocausto foi a forte influência do debate francês, especialmente em relação aos trabalhos que, inspirados por Pierre Vidal-Naquet (1988), procuravam refutar as teses negacionistas a partir da formação de uma genealogia crítica dos autores que se dedicaram a tentar provar que as mortes nos campos de concentração não passaram de uma mentira orquestrada pela comunidade judaica internacional (Moraes, 2013). Mesmo em menor escala, o negacionis- 
mo do genocídio armênio também foi explorado por historiadores brasileiros. A coletânea 100 Anos do genocídio armênio - negacionismo, silêncio e direitos Humanos 1915-2015 (Carneiro; Boucault; Loureiro, 2019) apresenta artigos de vários estudiosos que ajudam a compreender os mecanismos mobilizados pelo Estado turco-otomano para o assassinato de 1,5 milhão de armênios, entre 1915 e 1917, e as formas de sua negação.

Também no Brasil, a potencialidade das formas digitais de produção e de disseminação de informações tem sido decisiva na operacionalização de conteúdos negacionistas e de notícias falsas em geral, sem qualquer controle, através das redes sociais e de aplicativos de mensagens (Cesarino, 2020). Há uma sensível aceleração deste processo desde 2012, quando foi instalada a Comissão Nacional da Verdade, expressando-se, sobretudo, pelo crescimento de uma "comunidade de memória" de teor francamente negacionista sobre a ditadura militar brasileira (Pereira, 2015).

A negação do passado autoritário recente foi um dos eixos de constituição do bolsonarismo como um fenômeno político de extrema-direita, capaz de agregar forças sociais diversas como comunidades evangélicas, grande empresariado, militares e agronegócio (Klem; Pereira; Araújo, 2020). Em verdade, é impossível dissociar a própria persona política de Jair Bolsonaro do negacionismo/revisionismo ideológico da ditadura brasileira (Nascimento et al., 2018). Ao longo de sua carreira como deputado do chamado "baixo clero" da Câmara Federal, Bolsonaro mencionou o período militar em $25 \%$ dos seus discursos parlamentares, quase sempre tecendo elogios aos militares e ao combate à "subversão comunista". Este negacionismo da ditadura tem raízes nos esforços dos próprios militares em constituir uma memória que procurou dissociar o regime de suas feições autoritárias e repressivas (Schneider, 2020), "contribuindo para a conformação de certas impressões e representações presentes até os dias de hoje na memória social do período" (Bauer, 2020, p. 177).

Não parece uma simples coincidência, portanto, que uma das linhas recentes de força da historiografia brasileira que tem se debruçado sobre o negacionismo seja composta por pesquisadores dedicados ao estudo da ditadura militar (Bauer, 2018; Fico, 2021; Napolitano, 2021; Silva, 2021). As formas de negação mais rudes e primárias sobre 1964 e o período posterior alcançaram uma expressividade pública vista como improvável há alguns poucos anos atrás, e um dos seus mais eloquentes representantes se tornou Presidente da República. O caráter ainda recente dos acontecimentos negados por esta comunidade de memória implica também o trabalho de contraposição aos testemunhos que reivindicam lembranças do tipo "naquele tempo que era bom", 
que carregam a força da experiência, da afetividade e da fala em primeira pessoa como marcadores de autenticidade. Acompanhar a produção recente desses pesquisadores e suas intervenções no espaço público é, deste modo, um aspecto de grande importância em qualquer agenda de pesquisa sobre os negacionismos históricos e o revisionismo ideológico no Brasil contemporâneo.

O crescimento, nos últimos anos, desta memória que desvincula o período militar do seu caráter ditatorial e o associa a uma era de crescimento econômico, ordem social e orgulho patriótico, é inseparável da mobilização sistemática do universo midiático digital por parte de grupos conservadores e de extrema-direita (Fontoura, 2020; Rocha, 2021). Um exemplo impressionante é o documentário "1964 - O Brasil entre armas e livros", produzido pela empresa Brasil Paralelo, em 2019, e que já conta com quase nove milhões de visualizações na plataforma Youtube ${ }^{8}$, não obstante seu conteúdo amalgamado de revisionismos ideológicos e negacionismos já ter sido objeto de uma crítica historiográfica consistente (Nicolazzi, 2019; Paulo, 2020).

Deste modo, parece-nos que as pesquisas sobre as manifestações mais recente do fenômeno negacionista no Brasil não poderão abrir mão de uma investigação rigorosa das formas pelas quais o consumo de passados distorcidos e falseados se popularizou em níveis consideráveis ao longo da última década. ${ }^{9}$ Para tanto, a investigação deverá considerar a hipótese de a produção e a circulação desses passados encontrarem terreno fértil em uma historicidade atualista na qual o real se confunde com a atualidade vivenciada como um presente vazio e autocentrado (Pereira; Araújo, 2021).

O negacionismo bolsonarista, tragicamente espetacularizado na pandemia de COVID-19, dá forma a uma lógica de negação que antecede e extrapola a dimensão sanitária e se realiza, em nosso tempo presente, sob a forma de uma governamentalidade, entendida como "um conjunto de instituições, procedimentos, análises, e táticas que adquirem sentido e forma quando articulados pelo negacionismo histórico" (Valim; Avelar, 2020). Apelando a afetos e a emoções já presentes em parcelas significativas da população, esse negacionismo articula um conjunto amplo de representações sobre a vida social que reforçam uma identidade política radicalizada de extrema-direita (Caponi, 2020; Duarte; César, 2020; Szwako, 2020).

Como assinalam Mateus Pereira e Daniel Pinha Silva, em contribuição ao dossiê, o negacionismo brasileiro contemporâneo é também o signo de uma forma mais ampla - potencializada pela narrativa construída em torno da Operação Lava-Jato - de negação moralista da política, da vida institucional e dos agentes mediadores (Pereira; Silva, 2021). Estas reflexões talvez nos ajudem 
ainda a compreender uma outra dimensão relevante dos nossos negacionismos e revisionismos recentes: a tentativa recorrente de desqualificação, não apenas do conhecimento historiográfico produzido nas universidades brasileiras, mas também os próprios historiadores, vistos como portadores de interesses ocultos, "doutrinadores" e defensores de ideologias socialistas.

Outra chave importante para a construção de uma possível agenda brasileira de pesquisa sobre o tema do negacionismo é a investigação diacrônica de suas manifestações, levando-nos a entender como a própria construção de uma "retórica da nacionalidade" no século XIX realizou-se mediante sucessivas exclusões e negações dos papéis desempenhados por indígenas e negros na formação nacional. Tal discurso visava consolidar "uma imagem sem rasuras da nação, capaz de neutralizar todos os impasses na integração dos respectivos súditos em uma consciência nacional e histórica" (Cezar, 2018, p. 21). Essas formas de olhar para o presente e para o passado se definiam por uma certa política do tempo progressista, típica de uma elite que se enxergava capaz de inventariar um repertório de experiências comuns, negando as descontinuidades e tensões que "formariam uma história viva, abortada, em última instância e paradoxalmente, pela historiografia” (Cezar, 2018, p. 18).

Esse horizonte diacrônico remete a um espaço temporal de inteligibilidade mais largo, no qual se estruturam nossos negacionismos fundantes a respeito das comunidades negras e indígenas e os genocídios e silêncios dos quais foram historicamente vítimas. O artigo de Edson Holanda Lima Barboza e Silvana Fernandes Mariz é, sob estes aspectos, uma importante contribuição a esse dossiê, ao enfocar a persistência dos discursos que reproduziam as já conhecidas narrativas que negavam a presença dos negros na formação social do estado do Ceará e referendavam a hipótese de que os indígenas desapareceram ao entrarem em contato com os brancos durante a colonização portuguesa. $\mathrm{O}$ artigo se debruça especificamente sobre o livro O Cearense Revelado, de 2020, cujo autor, Luís Santos, defende a ideia de que, na constituição do povo cearense, houve uma predominância de elementos nórdicos, muito mais do que negros e indígenas. Esse estranho exercício genealógico reatualiza velhos esquemas discursivos negacionistas que legitimam "as desigualdades sociais e a subalternização dos povos indígenas e negros na contemporaneidade" (Barboza; Mariz, 2021, p. 112).

Frente aos desafios e impactos lançados pelos negacionistas, qual deve ser o papel de uma historiográfica criticamente orientada e ainda depositária de expectativas quanto à verdade dos seus enunciados e formulações? Não é despropositado, certamente, o alerta tão largamente difundido, segundo o qual o 
risco de responder diretamente às falsificações dos negacionistas é manter em evidência o que não deveria ser considerado um problema historiográfico. Outro temor é o de teorizarmos sobre processos ainda em curso. Assim, a reafirmação da cientificidade de uma história disciplinada seria o suficiente neste combate contra a mentira e a falsificação? Devemos acreditar que, ao fim e ao cabo, a história - com sua moralidade redentora - irá promover a justiça, restaurar a verdade e relegar os negacionistas à sua "lata do lixo" (Scott, 2020, p. xi)? Ou há mais em jogo? Que formas de representação do passado e de sua inscrição no espaço público podem ser mobilizadas? Estas questões foram os eixos das reflexões contidas no artigo de Arthur Avila, que fecha este dossiê e nos convida a pensar a noção de pluralismo historiográfico como uma possibilidade epistemológica de enfrentamento dos negacionismos, capaz de ampliar nossa imaginação política "sem obsessões com limites [...] disciplinares" (Avila, 2021, p. 164). As hipóteses de Avila são testadas em sua análise das formas pelas quais a empresa Brasil Paralelo, em seus vídeos, constrói uma narrativa "civilizatória" da escravidão e do passado colonial e monárquico.

Os debates sobre o papel da historiografia no combate ao negacionismo assumem ainda mais centralidade quando consideramos as implicações que a noção de pós-verdade alcançou, especialmente nas construções discursivas de um espaço midiático que foi irreversivelmente impactado pelas novas tecnologias de informação (Gudonis; Jones, 2020). Neste cenário, é imprudente que o negacionismo não seja tratado como uma questão historiográfica decisiva, sendo imperioso investigar sua "estrutura profunda" e seus significados retóricos e epistemológicos mais densos (Lang, 2010, p. 158). Uma via possível para a realização desta tarefa foi mobilizada por Eduardo Cardoso Wright que, em seu artigo para esse dossiê, retomou o debate nunca encerrado sobre as relações entre história, mentira e verdade. O percurso escolhido pelo autor consistiu, sobretudo, em investigar dois empreendimentos intelectuais fundamentais de enfrentamento das mentiras produzidas pelos negacionistas: aqueles levados a cabo por Pierre Vidal-Naquet e Deborah Lipstadt. As iniciativas desses dois historiadores são úteis, segundo Wright Cardoso, para a discussão de categorias centrais ao trabalho do historiador, tais como verdade, prova e autópsia, bem como para uma reavaliação crítica das "limitações institucionais na contínua e premente tarefa de identificar e combater a mentira" (Cardoso, 2021, p. 89).

O tema da verdade foi também o eixo da contribuição de Sônia Meneses. Em seu artigo, a autora abordou o problema a partir de uma imersão analítica a respeito dos princípios de veridicção que povoam o espaço público contem- 
porâneo, especialmente após a emergência de uma onda negacionista na década de 2010. A hipótese explorada por Meneses foi a de que vivemos uma crise dos modelos tradicionais estabelecidos por uma tecnologia da verdade, $o$ que Foucault denominou de "verdade demonstrativa" ou "verdade conhecimento". Se os regimes modernos de produção de enunciados verdadeiros parecem ter se esgotado ou, no mínimo, entrado em um estado profundo de desagregação, como serão impactados e reagirão a disciplina histórica e o jornalismo (Meneses, 2021)?

Essa apresentação e os artigos que fazem parte desse dossiê resultam de esforços intelectuais importantes, mas nem por isso desejáveis. As negações, falsificações e distorções de tantos passados representam desafios que não gostaríamos de enfrentar. Tampouco temos plena certeza de quais serão as armas que devemos empunhar e, menos ainda, se seremos exitosos. Nossos ensaios, artigos e livros continuarão a ser escritos na expectativa de que eles possam ser comprometidos não apenas com a erudição historiográfica apropriada diante dos negacionistas, mas também com a disposição incessante de honrar nossos mortos - por genocídios ou pandemias - e impedir que eles se tornem fantasmas a nos assombrar.

Boa leitura a todos!

\section{REFERÊNCIAS}

ATKINS, Stephen E. Holocaust Denial as an International Movement. London: Praeger, 2008.

AVILA, Arthur Lima de. Qual passado escolher? Uma discussão sobre o negacionismo histórico e o pluralismo historiográfico. Revista Brasileira de História, São Paulo, v. 41, no 87 , pp. 161-184, 2021.

BARBOZA, Edson Holanda Lima e MARIZ, Silviana Fernandes. No Ceará não tem disso não? Negacionismos e povos indígenas e negros na formação social do Ceará. Revista Brasileira de História, São Paulo, v. 41, no 87, pp. 111-134, 2021.

BARDĖCHE, Maurice. Nuremberg ou la terre promise. Paris: Les Sept Couleurs, 1948. BARUCH, Marc-Olivier. Des lois indignes? Les historiens, la politique et le droit. Paris: Tallandier, 2013.

BASER, Bahar. The Awakening of a Latent Diaspora: The Political Mobilization of First and Second Generation Turkish Migrants in Sweden. Ethnopolitics, v. 13, n. 4, pp. 355-376, 2014.

BAUER, Caroline Silveira. Enfrentando o "silêncio das sociedades perfeitas": a história pública e o revisionismo da ditadura civil-militar brasileira. In: MAUAD, Ana 
Maria; SANTHIAGO, Ricardo; BORGES, Viviane Trindade (Orgs.). Que história pública queremos?/What Public History Do We Want? São Paulo: Letra e Voz, 2018. pp. 1-10.

BAUER, Caroline Silveira. Usos do passado da ditadura brasileira em manifestações públicas de Jair Bolsonaro. In: KLEM, Bruna Stutz; PEREIRA, Mateus Henrique de Faria; ARAÚJO, Valdei Lopes (Orgs.). Do fake ao fato: (des)atualizando Bolsonaro. Vitória: Editora Milfontes, 2020. pp. 183-204.

BEHRENS, Paul. Why Not the Law? Options for Dealing with Genocide and Holocaust Denial. In: BEHRENS, Paul; TERRY, Nicholas; JENSEN, Olaf (Eds.). Holocaust and Genocide Denial: a Contextual Perspective. New York: Routledge, 2017. pp. 230-250.

BELAVUSAU, Uladzislau; GLISZCZYŃSKA-GRABIAS, Aleksandra. Introduction: Memory Laws: Mapping a New Subject in Comparative Law and Transitional Justice. In: Law and Memory: Towards Legal Governance of History. New York: Cambridge University Press, 2017. pp. 1-26.

BEVERNAGE, Berber. História, memória e violência de Estado: tempo e justiça. Vitória: Milfontes, 2018.

BUTZ, Arthur. The Hoax of the Twentieth Century: the Case against the Presumed Extermination of European Jewry. Torrance, California: Noontide Press, 1979.

CAPONI, Sandra. Covid-19 no Brasil: entre o negacionismo e a razão neoliberal. Estudos Avançados, v. 34. n. 99, pp. 209-224, 2020.

CARDOSO, Eduardo Wright. Em busca da mentira: historiadores contra a falsificação do Holocausto. Revista Brasileira de História, São Paulo, v. 41, nº 87, pp. 89-110, 2021.

CARNEIRO, Maria Luiza Tucci; BOUCAULT, Carlos Eduardo de Abreu; LOUREIRO, Heitor de Andrade Carvalho (Orgs.). 100 anos do genocídio armênio: negacionismo, silêncio e direitos humanos (1915-2015). São Paulo: Humanitas, 2019.

CARNEIRO, Maria Luiza Tucci. O anti-semitismo na Era Vargas (1930-1945). 3. Ed. São Paulo: Perspectiva, 2001.

CESARINO, Leticia. How Social Media Affords Populist Politics: Remarks on Liminality Based on the Brazilian Case. Trabalhos em Linguística Aplicada, v. 59, n. 1, pp. 404-427, 2020.

CEZAR, Temístocles. Ser historiador no século XIX: o caso Varnhagen. Belo Horizonte: Autêntica, 2018.

CHARNY, Israel W. (Ed.). Genocide, a Critical Bibliographic Review. London: Mansell, 1992.

COHEN, Stanley. States of Denial: Knowing about Atrocities and Suffering. Cambridge: Polity Press, 2001.

DAVID, Lea. Moral Remembrance and New Inequalities. Global Perspectives, v. 1, n. 1, pp. 1-15, 2020a. 
DAVID, Lea. The Emergence of the "Dealing With the Past" Agenda: Sociological Thoughts on Its Negative Impact on the Ground. Modern Languages Open, n. 1, pp. 1-14, 2020 b.

DUARTE, André de Macedo; CÉSAR, Maria Rita de Assis. Negação da política e negacionismo como política: pandemia e democracia. Educação \& Realidade, v. 45. n. 4, pp. 1-22, 2020.

FAURISSON, Robert. Écrits révisionnistes (1974-1998). Paris: R. Faurisson, 1999.

FEIERSTEIN, Daniel. Memorias y representaciones: sobre la elaboración del genocidio. Buenos Aires: Fondo de Cultura Económica, 2012.

FICO, Carlos. Quem escreve a história: a qualificação do historiador. In: PINSKI, Jaime; PINSKY, Carla Bassanezi (Orgs.). Novos combates pela história: Desafios Ensino. São Paulo: Contexto, 2021. pp. 25-47.

FINKIELKRAUT, Alain. The Future of a Negation: Reflections on the Question of Genocide. Lincoln: University of Nebraska Press, 1998 [1982].

FONTOURA, Odir. Narrativas históricas em disputa: um estudo de caso no Youtube. Estudos Históricos, v. 33, n. 69, pp. 45-63, 2020.

FRESCO, Nadine. Les redresseurs de morts. Chambres à gaz: la bonne nouvelle. Comment on révise l'histoire. Les Temps Modernes, n. 407, 1980.

FRIEDLÄNDER, Saul. Probing the Limits of Representation: Nazism and the "Final Solution". Cambridge: Harvard University Press, 1992.

FRONZA, Emanuela. Memory and Punishment: Historical Denialism, Free Speech and the Limits of Criminal Law. The Hague: TMC Asser Press; Berlin: Springer, 2018. GIBNEY, Mark et al. (Eds.). The Age of Apology: Facing Up to the Past. Philadelphia: University of Pennsylvania Press, 2008.

GODDEERIS, Idesbald. History Riding on the Waves of Government Coalitions: The First Fifteen Years of the Institute of National Remembrance in Poland (20012016). In: BEVERNAGE, Berber; WOUTERS, Nico (Eds.). The Palgrave Handbook of State-Sponsored History after 1945. London: Palgrave Macmillan, 2018. pp. 255-269.

GUDONIS, Marius; JONES, Benjamin T. (Eds.). History in a Post-Truth World: Theory and Praxis. New York: Routledge, 2020.

HASSAN, Claudia Gina. The Dark Side of the Internet. International Journal of Psychoanalysis and Education, v. 8, n. 2, pp. 14-23, 2016.

HAYASHI, Hirofumi. Disputes in Japan over the Japanese Military "Comfort Women" System and Its Perception in History. The ANNALS of the American Academy of Political and Social Science, v. 617, n. 1, pp. 123-132, 2008.

HENNEBEL, Ludovic; HOCHMANN, Thomas (Eds.). Genocide Denials and the Law. Oxford: Oxford University Press, 2011.

IGOUNET, Valérie. Le négationnisme en France. Paris: Humensis, 2020.

IRVING, David. Hitler's War. New York: Viking Press, 1977. 
JESUS, Carlos Gustavo Nóbrega de. Anti-semitismo e nacionalismo, negacionismo e memória: Revisão Editora e as estratégias da intolerância (1987-2003). São Paulo: Editora da UNESP, 2006.

KLEM, Bruna Stutz; PEREIRA, Mateus; ARAUJO, Valdei (Orgs.). Do fake ao fato: (des) atualizando Bolsonaro. Vitória: MilFontes, 2020.

KOINOVA, Maria. Diaspora Coalition-Building for Genocide Recognition: Armenians, Assyrians and Kurds. Ethnic and Racial Studies, v. 42, n. 11, pp. 1890-1910, 2019.

KOPOSOV, Nikolay. Populism and Memory: Legislation of the Past in Poland, Ukraine, and Russia. East European Politics and Societies and Cultures, v. 20, n. 10, pp. 1-26, 2021.

KÜNTZEL, Matthias. Judeophobia and the Denial of the Holocaust in Iran, In: WISTRICH, Robert S. (Ed.). Holocaust Denial: the Politics of Perfidy. Jerusalem: Berlin: Boston: De Gruyter, 2012. pp. 235-255.

KUPER, Leo. Genocide: Its Political Use in the Twentieth Century. New Haven, Conn: Yale University Press, 1981.

KURADUSENGE, Claudine. Denied Victimhood and Contested Narratives: The Case of Hutu Diaspora. Genocide Studies and Prevention: An International Journal, v. 10, n. 2, pp. 59-75, 2016.

LACZÓ, Ferenc. Caught between Historical Responsibility and the New Politics of History: on Patterns of Hungarian Holocaust Remembrance. In: MITROIU, Simona (Ed.). Life Writing and Politics of Memory in Eastern Europe. London: Palgrave Macmillan, 2015. pp 185-201.

LANG, Berel. Six Questions on (or about) Holocaust Denial. History and Theory, v. 49, n. 2, pp. 157-168, 2010.

LANGER, Lawrence L. Admitting the Holocaust: Collected Essays. New York: Oxford University Press, 1995.

LEMKIN, Raphaël. Axis Rule in Occupied Europe: Laws of Occupation, Analysis of Government, Proposals for Redress. Publications of the Carnegie Endowment for International Peace, Division of International Law. New York: Columbia University Press, 1944.

LIPSTADT, Deborah. Denying the Holocaust: the Growing Assault on Truth and Memory. London: Plume, 1994.

LOUREIRO, Heitor de Andrade Carvalho; ZAGNI, Rodrigo Medina. Artífices de conceitos: a invenção do conceito de genocídio e sua aplicação aos estudos históricos. Revista Fórum de Ciências Criminais, Belo Horizonte, ano 6, n. 12, pp. 149-176, 2019.

MENESES, Sônia. Os vendedores de verdades: o dizer verdadeiro e a sedução negacionista na cena pública como problema para o jornalismo e a história (2010-2020). Revista Brasileira de História, São Paulo, v. 41, nº 87, pp. 61-87, 2021. 
MILMAN, Luís (Org.). Ensaios sobre o anti-semitismo contemporâneo. Porto Alegre: Sulina, 2004.

MILMAN, Luís. Negacionismo: gênese e desenvolvimento do extermínio conceitual. In: MILMAN, Luís; VIZENTINI, Paulo Fagundes (Orgs.). Neonazismo, negacionismo e extremismo político. Porto Alegre: Editora da UFRGS: Corag, 2000. pp. 123-164.

MILMAN, Luís; VIZENTINI, Paulo Fagundes (Orgs.). Neonazismo, negacionismo e extremismo político. Porto Alegre: Editora da UFRGS: Corag, 2000.

MOON, Claire. States of Acknowledgement: the Politics of Memory, Apology, and Therapy. In: DOWNES, David et al. (Eds.). Crime, Social Control and Human Rights: from Moral Panics to States of Denial. Essays in Honour of Stanley Cohen. London: Routledge, 2013.

MORAES, Luís Edmundo de Souza. Lembrar o Holocausto hoje. Revista Eletrônica do NIEJ, v. 1, n. 1, pp. 16-19, 2009.

MORAES, Luís Edmundo de Souza. Negacionismo: a extrema-direita e a negação da política de extermínio nazista. Boletim do Tempo Presente, n. 4, pp. 1-22, 2013.

NAFTALI, Patricia. The "Right to Truth" in International Law: the "Last Utopia"? In: BELAVUSAU, Uladzislau; GLISZCZYŃSKA-GRABIAS, Alexsandra (Eds.). Law and Memory: towards Legal Governance of History. New York: Cambridge University Press, 2017. pp. 70-88.

NAPOLITANO, Marcos. Negacionismo e revisionismo histórico no século XXI. In: PINSKY, Jaime; PINSKY, Carla Bassanezi (Orgs.). Novos combates pela história: Desafios - Ensino. São Paulo: Contexto, 2021. pp. 85-111.

NARLOCH, Leandro. Guia Politicamente Incorreto da História do Brasil. São Paulo: LeYa, 2009.

NASCIMENTO, Leonardo et al. "Não falo o que o povo quer, sou o que o povo quer": 30 anos (1987-2017) de pautas políticas de Jair Bolsonaro nos jornais brasileiros. Plural, v. 25, n. 1, pp. 135-171, 2018.

NASCIMENTO, Abdias do. O genocídio do negro brasileiro: processo de um racismo mascarado. São Paulo: Perspectiva, 2016 [1978].

NEHAB, Werner. Anti-Semitismo, Integralismo, Neo-Nazismo: Rio de Janeiro: Livraria Freitas Bastos, 1988.

NETO, Mario Marcello. Entre a bomba atômica e os crimes de guerra: o negacionismo e a historiografia japonesa em perspectiva. Revista Brasileira de História, São Paulo, v. 41, no 87 , pp. 37-60, 2021.

NETO, Odilon Caldeira. Memória e justiça: o negacionismo e a falsificação da história. Antíteses, v. 2, n. 4, pp. 1097-1123, 2009.

NICHANIAN. Marc. La perversion historiographique: une réflexion arménienne. Paris: Lignes \& Manifestes, 2006. 
NICHOLS, Tom. The Death of Expertise: the Campaign against Established Knowledge and why it Matters: New York: Oxford University Press, 2017.

NICOLAZZI, Fernando. A história da ditadura contada pela Brasil Paralelo. 23 mar. 2019. Disponível em: https://www.sul21.com.br/opiniaopublica/2019/03/a-historia-da-ditadura-contada-pelo-brasil-paralelo-por-fernando-nicolazzi/. Acesso em: 9 mai. 2021.

OLICK, Jeffrey K. The Politics of Regret: on Collective Memory and Historical Responsibility. New York: London: Routledge, 2013.

PAULO, Diego Martins Dória. Os mitos da Brasil Paralelo - uma face da extrema-direita brasileira (2016-2020). Rebela, v. 10, n. 1, pp. 101-110, 2020.

PEREIRA, Mateus Henrique de Faria. Nova direita? Guerras de memória em tempos de Comissão da Verdade (2012-2014). Varia historia, vol. 31, n. 57, pp. 863-902, 2015.

PEREIRA, Mateus Henrique de Faria; ARAÚJO, Valdei Lopes de. Atualismo: pandemia e historicidades no interminável 2020. Estudos Ibero-Americanos, Porto Alegre, v. 47, n. 1, pp. 1-16, 2021.

PEREIRA, Mateus Henrique de Faria; SILVA, Daniel Pinha. Sérgio Moro negacionista? Operação Lava-Jato, transparência atualista e negação da política. Revista Brasileira de História, São Paulo, v. 41, nº 87, pp. 135-159, 2021.

QUAMAR, Muddassir. Holocaust Denial and Minimization in the Indian Urdu Press. In: AAFREDI, Navras J.; SINGH, Priya (Eds.). Conceptualizing Mass Violence: Representations, Recollections, and Reinterpretations. London: Routledge, 2021. pp. 87-96.

RASSINIER, Paul. Le mensonge d'Ulysse. 7. Ed. Paris: La Vieille Taupe, 1987.

RATEAU, Paul. La vérité, le mensonge et la loi. Les Temps Modernes, $62^{\mathrm{e}}$ année, $\mathrm{n}$. 645-646, pp. 26-58, 2007.

ROCHA, João Cezar de Castro. Guerra cultural e retórica do ódio: crônicas de um Brasil pós-político. Goiânia: Caminhos, 2021.

ROSENFELD, Gavriel D. The Rise of Illiberal Memory. Memory Studies, pp. 1-18, 2021. ROUSSO, Henry. Foreword. In: GUDONIS, Marius; JONES, Benjamin T. (Eds.). History in a Post-Truth World: Theory and Praxis. New York: Routledge, 2020. pp. xiii-xv.

ROUSSO, Henry. Le syndrome de Vichy (1944-1987). Paris: Seuil, 1987.

ROUSSO, Henry. Les racines du négationnisme en France. In: Face au passé: essais sur la mémoire contemporaine. Paris: Belin, 2016. pp. 165-192.

SANTOS, Luís Sérgio. O Cearense Revelado: uma jornada via DNA desvenda nossa ancestralidade. Fortaleza: Instituto Myra Eliane, 2020.

SCHABAS, William A. Genocide in International Law: The Crime of the Crimes. New York: Cambridge University Press, 2000. 
SCHAUB, Max; MORISI, Davide. Voter Mobilisation in the Echo Chamber: Broadband Internet and the Rise of Populism in Europe. European Journal of Political Research, v. 59, n. 4, pp. 752-773, 2020.

SCHNEIDER, Nina. Bolsonaro in Power: Failed Memory Politics in Post-Authoritarian Brazil? Modern Languages Open, n. 1, pp. 1-11, 2020.

SCOTT, Joan Wallach. On the Judgment of History. New York: Columbia University Press, 2020.

SILVA, Marcos. Ditadura relativa e negacionismos: Brasil, 1964 (2016, 2018...). São Paulo: Maria Antônia Edições, 2021.

SZWAKO, José. O que nega o negacionismo. Cadernos de Subjetividades, v. 1, n. 21, pp. 71-78, 2020.

TERRY, Nicholas. Holocaust Denial in the Age of Web 2.0: Negationist Discourse since the Irving-Lipstadt Trial. In: BEHRENS, Paul; TERRY, Nicholas; JENSEN, Olaf (Eds.). Holocaust and genocide denial: a contextual perspective. New York: Routledge, 2017. pp. 34-54.

THUS, Valeria. El antinegacionismo jurídico: Reflexiones político-criminales en torno a la prevención de genocidios. JORNADAS DE JÓVENES INVESTIGADORES, VII, 2013, Instituto de Investigaciones Gino Germani, Facultad de Ciencias Sociales, Universidad de Buenos Aires, Buenos Aires.

TRAVERSO, Enzo. The New faces of Fascism: Populism and the Far Right. London: New York: Verso, 2019.

VALIM, Patricia; AVELAR, Alexandre de Sá. Negacionismo Histórico: entre a governamentalidade e a violação dos direitos fundamentais. Revista Cult, São Paulo, pp. 1-5, 3 set. 2020.

VENÂNCIO, Renato. O incorreto no Guia politicamente incorreto da história do Brasil. 9 nov. 2018. Disponível em: https://hhmagazine.com.br/o-incorreto-no-guia-politicamente-incorreto-da-historia-do-brasil/. Acesso em: 9 de maio de 2021.

VIDAL-NAQUET, Pierre. Os assassinos da memória: um Eichmann de papel e outros ensaios sobre o revisionismo. Campinas: Papirus, 1988.

WISTRICH, Robert S. (Ed.) Holocaust Denial: the Politics of Perfidy. Jerusalem: Berlin; Boston: De Gruyter, 2012.

\section{NOTAS}

${ }^{1}$ Deborah Lipstadt (1994) demonstrou que os negacionistas do Holocausto viam-se como herdeiros intelectuais de uma tradição revisionista que se estabeleceu na historiografia norte-americana a partir dos anos 20 e que se caracterizou pela reinterpretação da culpa alemã pela eclosão da I Guerra Mundial. Representantes dessa tradição, como Sidney B. Fay, Harry Elmer Barnes, Charles Beard, entre outros, não apenas minimizaram a respon- 
sabilidade dos alemães pelo conflito como foram muito críticos aos Aliados, apontados como dúbios e belicosos.

2 Sobre a definição do paradigma "onusiano" de genocídio e as suas implicações na construção do paradigma do objeto a ser negado pela geração de negacionistas profissionais, são marcos importantes: a Convention on the Prevention and Punishment of the Crime of Genocide, da mesma assembleia, de 1951; o julgamento de Adolf Otto Eichmann, em Jerusalém, no ano de 1968; o Revised and Updated Report on the Question of the Prevention and Punishment of the Crime of Genocide, elaborado por Benjamin Whitaker para a ONU entre os anos de 1985 e 1986; o processo Prosecutor X Krstic, de 2004, que versou sobre a ocorrência do genocídio, em 1995, em Srebrenica; o Report of the International Commission of Inquiry on Darfur to the United Nations Secretary-General, elaborado de acordo com a resolução 1564, do Conselho de Segurança da ONU, de 2004; e, por fim, a Declaration on Prevention of Genocide, elaborada pelo Committee for the Elimination of Racial Discrimination, de 2005.

${ }^{3}$ As análises dos genocide scholars sugerem que o paradigma "onusiano" de genocídio em relação ao Holocausto foi fundamental para a constituição de um grupo de negacionistas profissionais com considerável espaço na esfera pública (Loureiro; Zagni, 2019; Feierstein, 2012; Charny, 1992).

${ }^{4}$ A negação do Holocausto está em ascensão em lugares como o Irã e o mundo árabe (onde as tensões ao redor da ocupação israelense de territórios palestinos provaram ser um terreno fértil para sua expansão), mas também em países como o Canadá, a Austrália, a África do Sul, a Índia e o Japão (Wistrich, 2012; Quamar, 2021).

${ }^{5}$ Nome dado às mulheres que foram feitas escravas sexuais pelo exército japonês, nos países e territórios ocupados, durante a II Guerra Mundial.

${ }^{6} \mathrm{O}$ "direito à verdade" foi pioneiro no contexto de iniciativas de justiça de transição na América Latina - principalmente na Corte Interamericana de Direitos Humanos. Atualmente, está cada vez mais incorporado à legislação internacional dos direitos humanos e é aplicado para muitos fins jurídicos diferentes. Considerando que foi concebido principalmente como um meio de impor que os estados revelassem o destino dos desparecidos, ele é também mobilizado por "ativistas da verdade" em todo o mundo, como um instrumento-chave para combater fenômenos mais amplos de negacionismo de Estado, bem como para exigir acesso à informação de forma mais geral, apoiar demandas legais para a reabertura de processos judiciais há muito encerrados ou exigir novas investigações sobre injustiças históricas (Naftali, 2017).

${ }^{7}$ Convém observar que as "leis memoriais" não se referem exclusivamente às leis anti-negacionistas, mas também àquelas que normatizam alguma forma de memória reconhecida do passado, como, por exemplo, as leis que, em muitos países, declaram a escravidão crime contra a humanidade. O termo, embora também presente no campo jurídico, é mais utilizado entre os historiadores.

${ }^{8} \mathrm{O}$ documentário em questão é o sétimo e último de uma série intitulada "Brasil: a última 


\section{Apresentação}

cruzada", lançada em 2017 com a ambiciosa proposta de oferecer uma reinterpretação da história do Brasil desde o período colonial.

${ }^{9} \mathrm{Um}$ dos marcos dessas produções que mesclam revisionismo ideológico e negacionismo é o conhecido livro de Leandro Narloch (2009) que, no ano de 2019, completou a significativa marca de um milhão de exemplares vendidos. Em 2017, a History Channel lançou um documentário inspirado no livro. Importante resposta ao negacionismo/revisionismo ideológico do livro de Narloch foi oferecida por Venâncio (2018). 